Journal of Engineering and Applied Sciences 15 (7): 1622-1625, 2020

ISSN: 1816-949X

(C) Medwell Journals, 2020

\title{
Learning the Malay Traditional Musical Instruments by using Augmented Reality Application
}

\author{
Masyarah Zulhaida Masmuzidin, Nur Syahela Hussein and \\ Alia Amira Abd Rahman and Mohamad Aqqil Hasman \\ Creative Multimedia Section, Malaysian Institute of Information Technology (MIIT), \\ University Kuala Lumpur, Kuala Lumpur, Malaysia
}

\begin{abstract}
This study proposed the implementation of Augmented Reality (AR) technology to promote the learning experience about Malay traditional musical instruments. The application uses a book as a marker to help the user visualizes the traditional musical instruments, learn the history behind it and how the instruments sounds. As a starting point, a library research has been conducted in order to understand the current state of the art. ADDIE Model has been used and the design and development phases has also been discussed. This AR application is expected to be a tool for promoting the Malay traditional musical instruments for the new young generation.
\end{abstract}

Key words: Augmented reality, Malay musical instruments, digital heritage, music, traditional

\section{INTRODUCTION}

Malaysia is a multi-racial country and is well known for the richness of its art, culture and heritage. For example, Malaysia has a wide range of unique traditional musical instruments that belong to the Malays, Chinese, Indians and from other ethnics. Rebana, Kompang and CakLempong (Malays society); Erhu, Bo, Ching and Chap (Chinese society) and Sitar, Dholak and Tabla (Indian society) are a few example of instruments that still exists in this country and more than 1.500 traditional musical instrument can be find and currently exhibit in Malaysia National Museum.

In Malaysia, traditional musical instruments are cultural musical tools. It serves as an entertainment and communication channel with a way of accompanying the performing arts in the local community through the production of a wide range of sound strains. However, traditional musical instruments have been slowly being forgotten. According to Raja Mohd Yusof one of the reason is caused by the lack of documentation on how to learn musical instruments. Previously, people learn about the instrument directly from the elders pass by from one generation to another and now, many information has lost and make Malay traditional musical instrument less popular.

In order to preserve the culture that have been practice since hundred years ago, the government of Malaysia has made few endeavors. For example, the traditional musical instruments from each ethnic has been introduced as a part of civic syllabus in preschool, primary and secondary school. The implementation of this syllabus can encourage the young generation to learn about their traditional musical instruments.

In terms of promoting the beauty of Malaysia cultures in the eyes of the world, many exhibition has been done by the government agencies. The Department of Malaysia Museums, for example has 1.500 collections of traditional Malaysian musical instruments from various races and ethnic groups with 200 of them exhibited at the Museum of Music and all over the country. Finally, a few books and research articles regarding traditional musical instrument has been published through various publications.

Besides all these endeavor, we have been motivated to introduces a new way for learning the history of Malaysian traditional musical instrument by using a new medium like Augmented Reality (AR). By using this technology, the users, especially, tourist and the new young generation can learn about the musical instrument in fun interactive way. Users does not have to go to the museum in order to see the instruments anymore, as they can see the instrument by using this technology. AR has been chosen because this technology can provide the realism of each the instruments developed in the application. As a start, this research focused on the development of the Malays traditional musical instruments.

Research objectives: In order to ensure that the aim of this research can be achieved, therefore three objectives have been developed. The first and second objective will be discussed in the next few sections and the third objective will be reported separately. The objectives of this research can be seen as follows: 
- To design a book which contain the information of the Malays traditional musical instruments

- To develop an AR application for learning the Malays traditional musical instruments

- To evaluate the usability of AR application for the Malays traditional musical instruments

\section{Literature review}

AR definition: In order to know more about this technology, we must have a clear understanding about the definition of this technology. According to Wu et al. (2013), one of the common used definitions for AR came from Milgram and Kishino (1994) work by using the virtuality continuum.

In virtuality continuum, real environments are shown at one end of the continuum at it defines any environments that consisting a real object like a video display. On the other hand, virtual environment defines environments that consist virtual objects like a simulation. Meanwhile, mixed reality or the common term augmented reality refer to any case in which an otherwise real environment is "augmented" by means of virtual (computer graphics) (Milgram and Kishino, 1994).

Besides virtuality continuum, another common definition is based on Azuma's works. This definition is defined based on its characteristics. According to Azuma (1997), any AR technology must have the following characteristics: combines real and virtual, is interactive in real time and is registered in three dimension (Fig. 1).

AR and traditional musical instrument: In this research, we reviewed articles from various online databases in order to identify the existing work related to this research. As a start, we used the terminology like "Augmented Reality" and "Traditional Musical Instruments". Based on these keywords we found a few articles that can be related to this research. and we found that research related to musical instruments can be found in two directions: using technology to preserve and promote musical instrument and using technology to learn about musical instruments.

By Phunsa designed an AR postcard in order to promote Thailand traditional musical instrument. Their works was developed by using Aurasma and consists of 11 instruments such as Pong Lang, Phin, Wode and Kaen. This application allows the user to view the media as video, 3D modeling and original sound when they scanning the marker (postcard).

By Putra et al. (2015) has developed virtual air kendang by using AR ToolKit. Their research was focused on kendang, a traditional musical instruments in Indonesia. In order to use the application, the user can begin with scanning a marker. If the marker detected, a 3D object will appear. The interesting element of virtual air kendang is the user interaction. This AR application

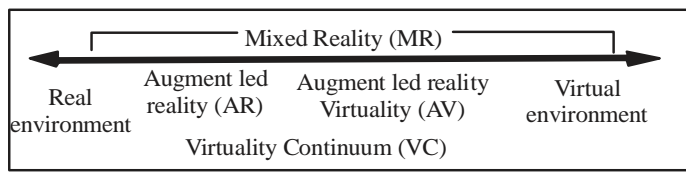

Fig. 1: Virtuality continuum (Milgram and Kishino 1994)

Table 1: AR and traditional musical instruments research

\begin{tabular}{lll}
\hline Researchers & Country & Purposes \\
\hline Phunsa (2014) & Thailand & $\begin{array}{l}\text { Promoting instruments by } \\
\text { using AR postcard }\end{array}$ \\
Zhang et al. (2015) & Indonesia & $\begin{array}{l}\text { Learn on how to play } \\
\text { instrument called kendang } \\
\text { Learn on how to play } \\
\text { Tan and Lim (2018) }\end{array}$ \\
& Malaysia & $\begin{array}{l}\text { instrument called guqin } \\
\text { Learn about history of } \\
\text { traditional instrument }\end{array}$ \\
\hline
\end{tabular}

create a high level of interaction which allows user play the kendang by hitting on the 3D Model. The user can hear the sound of kendang when their hand touch the side of the instruments.

Another research has been found in 2015. However, this research is not conducted to promote or preserve traditional musical instrument but it is developed for teaching and learning purposes. According to Zhang et al. (2015), Guqin is the traditional China musical instrument is hard to be learn and this has made it less popular. In order to help the user to learn this instruments more easily (Zhang et al., 2015) develop this technology.

By Tan and Lim (2018) has used AR technology to promote music educational musical instruments. This application has been developed by using Blender and Unity. According to Tan and Lim (2018), Malaysian Music Augmented Reality or MMAR has been found attractive. Based on the observation, they found that children can differentiate the instruments correctly. However, in terms of usability children has found few difficulties. For instance, children faced difficulties performing the activities due to inadequate light. This has made the children to scan the marker more than twice in order to see the 3D objects (Table 1).

\section{MATERIALS AND METHODS}

In this research, ADDIE Model has been used as a guideline to develop the AR application. This model has been selected because ADDIE Model is simple to be used and is well known in the development of many research development (Saidin et al., 2016). ADDIE Model consists of five phases and they are: analysis, design, development implementation and evaluation as shown in Fig. 2. The explanation for each phases are as follows.

Analysis phase: In the analysis phase, the target user has been identified and user requirement has been analyzed. Next, in order to identify which tools will be used in the 


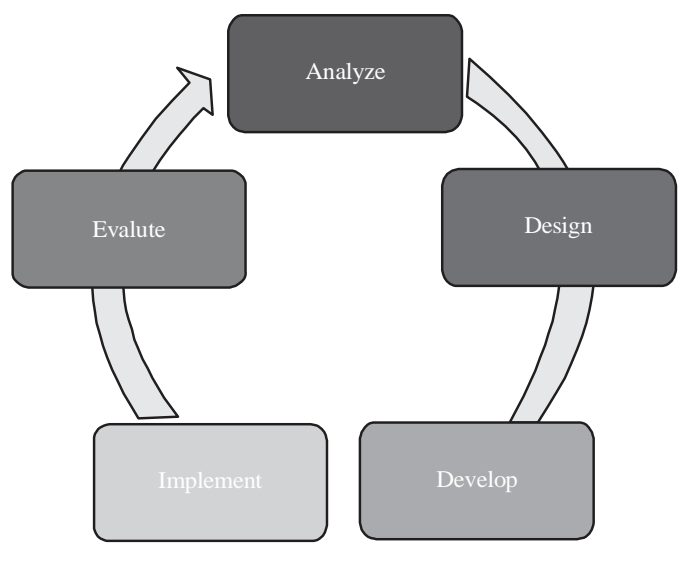

Fig. 2: ADDIE Model

Table 2: Examples of Malays traditional musical instruments based on its categories

\begin{tabular}{ll}
\hline Categories & Examples \\
\hline Membranophones & Rebana, kompang, beduk \\
Idiophones & Gong, simbal, loceng, canang, angklung \\
Chordophones & Gambus, rebab \\
Aerophones & Serunai, seruling \\
\hline
\end{tabular}

development of the AR application, an analysis has been conducted. The tools that will be used is unity and Vuforia SDK for AR. Meanwhile adobe photoshop and adobe illustrator will be used for design the book and markers. Finally, adobe premiere will be used for video editing.

For the content, only four musical instruments will be included and they are based on their categories. According to Salleh et al. the Malays traditional musical instruments can be classified into four categories: membranophones, idiophones, chordophones and aerophones. As there are many musical instruments exists, in this research, one instrument has been selected to represent for each category which are: rebana, gong, gambus and seruling (Table 2).

Design phase: In design phase, there are two parts of designing which are the design of the book and the design for AR application. For the book, a layout has been developed for each pages to ensure that the book design is consistent as shown in Fig. 3. The book and the marker has been designed by using adobe photoshop and illustrator.

Meanwhile, for the 3D Model, the instrument has been designed based on the real objects. In the AR application, there were two parts where the user can interact with, the 'Rotate' button and the 'Sound' button (Fig. 4).

Development phase: All the content designed in the previous phase will be use in the development phase. The target image or marker has been imported to unity and

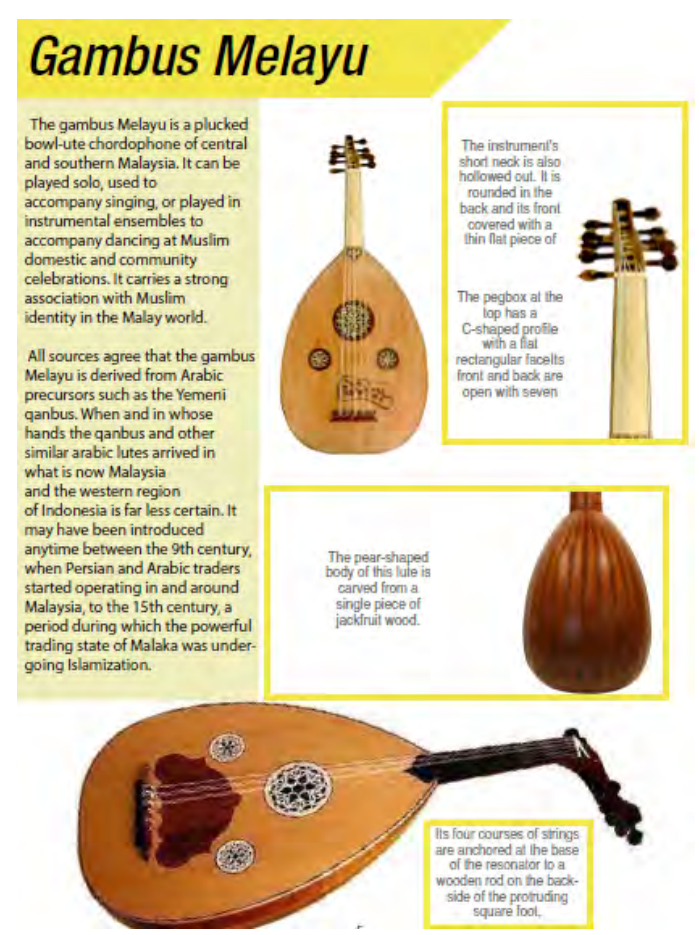

Fig. 3: An example of the book design

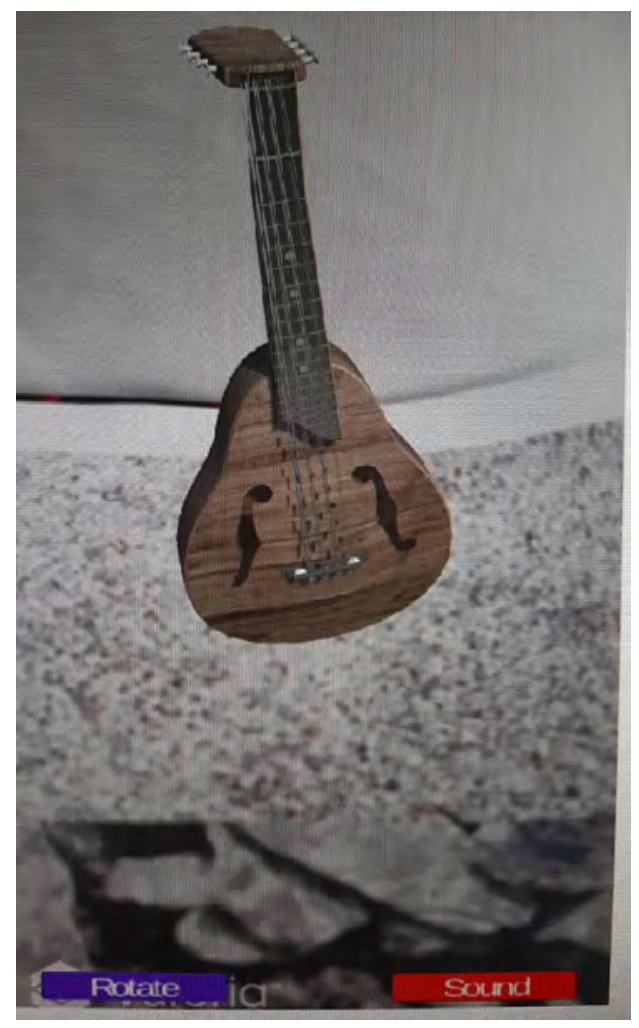

Fig. 4: An example of AR Graphic User Interface (GUI) 
Vuforia. The design of the marker must be clear and need to achieve 5 stars, so that, when user scan the marker, it can be detected easily.

Next, for the instruments, it has been developed by using 3D Max Studio. The 3D Model has been imported to unity. The imported model needs to be resized in order to ensure it is positioned correctly.

Implementation phase: This phase encompasses review and testing to ensure that the material; the book and the AR application is ready to be used. In order to use the AR application, the user need to scan the target image. In their phone, they will see a 3D object. They will be given two options. First, if the user wants to see the whole model, they can press 'Rotate' button to see the 3D object in $360^{\circ}$ view. Secondly, they also can hear the sound for the targeted 3D object when they press 'Sound' button.

\section{RESULTS AND DISCUSSION}

Evaluation phase: An evaluation has been conducted in order to understand the usability of the AR application at Universiti Kuala Lumpur, Malaysia with the involvement of five volunteers. All of the users have an experience using AR.

The users have been given 10-15 min to explore the AR application. After using the AR application, they were asked to answer a questionnaire. Based on the questionnaire, we found that $96 \%$ has agree that the application design is attractive. However, 57.1\% agreed that more content should be included. Finally, 80.2\% agreed that this application can help to promote the Malays traditional musical instruments to the young generation.

\section{CONCLUSION}

AR is a technology that has been widely use in the research regarding musical instrument. As a forementioned, this technology can be used for promoting and preserving the traditional musical instrument and it also can be used to teach the new generation on how to play the instrument. By the development of this application, it can be used widely not only for the use of young Malaysian but also can be used for other people from all around the world.

\section{RECOMMENDATIONS}

Base on the feedback from the user, there are few things that we need to consider for the improvement. Firstly, this AR application will be tested with the large sample. Secondly, we will develop more instruments from another races like Erhu from Chinese and Tabla from Indian society. Thirdly, we will develop much more interesting interaction such as the user can play with the instruments whenever they touch the 3D Model.

\section{ACKNOWLEDGEMENT}

I would like to thank Universiti Kuala Lumpur (Malaysian Institute of Information Technology) for co-funding this research.

\section{REFERENCES}

Azuma, R.T., 1997. A survey of augmented reality. Presence: Teleoperat. Virtual Environ., 6: 355-385.

Milgram, P. and A.F. Kishino, 1994. Taxonomy of mixed reality visual displays. IEICE Trans. Inform. Syst., E77-D: 1321-1329.

Phunsa, S., 2014. Applying augmented reality technology to promote traditional Thai folk musical instruments on postcards. Proceedings of the International Conference on Computer Graphics, Multimedia and Image Processing (SDIWC14), November 17-19, 2014, Kuala Lumpur, Malaysia, pp: 64-68.

Saidin, N.F., N.D.A. Halim and N. Yahaya, 2016. Designing Mobile Augmented Reality (MAR) for Learning Chemical Bonds. In: Proceedings of the 2nd International Colloquium of Art and Design Education Research (i-CADER'15), Abidin, S.Z., R. Legino, H.M. Noor, V.V. Vermol, A. Rusmadiah and M.F. Kamaruzaman (Eds.). Springer, Singapore, ISBN: 978-981-10-0237-3, pp: 367-377.

Tan, K.L. and C.K. Lim, 2018. Development of traditional musical instruments using Augmented Reality (AR) through mobile learning. AIP. Conf. Proc., Vol. 2016, No. 1. 10.1063/1.5055542

Wu, H.K., S.W.Y. Lee, H.Y. Chang and J.C. Liang, 2013. Current status, opportunities and challenges of augmented reality in education. Comput. Educ., 62: 41-49.

Zhang, Y., S. Liu, L. Tao, C. Yu, Y. Shi and Y. Xu, 2015. ChinAR: Facilitating Chinese Guqin learning through interactive projected augmentation. Proceedings of the 3rd International Symposium of Chinese (CHI'15), April 18-19, 2015, ACM, Seoul, South Korea, pp: 23-31. 